\title{
IS ARFI A USEFUL TOOL FOR NON-INVASIVE EVALUATION OF LIVER STIFFNESS IN NONALCOHOLIC FATTY LIVER DISEASE AND HEPATITIS C?
}

\author{
Coskun OZTURKER ${ }^{1}$, Ergenekon KARAGOZ ${ }^{2}$ and Huseyin Onur SILDIROGLU ${ }^{3}$
}

Received 24/4/2016 Accepted 4/5/2016

We have read the article by Guerra et al. with interest in a recent issue of the Arquivos de Gastroenterologia ${ }^{(2)}$. They concluded that acoustic radiation force impulse (ARFI) was useful tools to stage the severity of fibrosis in patients with non-alcoholic fatty liver disease (NAFLD) and chronic hepatitis C (CHC). We would like to thank the authors for their invaluable contribution. However, we would like to report few concerns regarding this study from a methodological point of view.

First, it would have been relevant, if the sample size of $\mathrm{CHC}$ patients had been larger.

Second, it would also have been better, if separate comparison of subgroups (CHC and NAFLD) had been made while evaluating patient group according to fibrosis score by ARFI technique. Additionally, it is stated in the present study that the measurements of Acoustic Radiation Force Impulse (ARFI) were performed in the right liver lobe through the intercostal space in the left lateral decubitus position ${ }^{(2)}$. In contrast to this study, Uslu et al demonstrated that subcostal approach to the liver parenchyma was significantly superior to intercostal approach for the evaluation of stiffness ${ }^{(5)}$. If the ARFI measurements had been performed through the subcostal space, the pressure would have been transmitted better to liver parenchyma, and this would have given better results than intercostal approach in terms of determining the elasticity of the liver.

Third, the length of the biopsy material was not mentioned in present study. Bedossa et al. demonstrated $40 \mathrm{~mm}$ long biopsy was considered an optimal specimen for accurate evaluation of liver fibrosis in the same study ${ }^{(3)}$. Additionally, the number of the pieces of the portal tracts was at least seven in present study.

According to American Association of Study of Liver Disease guidelines, an adequate number of portal tracts has been proposed to be greater than $11^{(3)}$. It would have been better, if the authors had been mentioned these constitute limitations in the study.

Last, Trovato et al. demonstrated that ARFI of the spleen is correlated with fibrosis staging, and could be a possible additional tool for the diagnosis of liver fibrosis ${ }^{(4)}$. It would have been useful, if the authors had evaluated their patients according to spleen measurements of these techniques.

Ozturker C, Karagoz E, Sildiroglu HO. O exame de sonoelastografia (ARFI) é uma ferramenta valiosa para avaliação da fibrose na doença hepática gordurosa não alcoólica e na hepatite C? Arq Gastroenterol. 2016,53(3):212.

\section{REFERENCES}

1. Bedossa P, Dargere D, Paradis V. Sampling variability of liver fibrosis in chronic hepatitis C. Hepatology. 2003;38:1449-57.

2. Guerra JA, Trippia M, Pissaia A, Teixeira BC, Ivantes CA. Acoustic radiation force impulse is equivalent to liver biopsy to evaluate liver fibrosis in patients with chronic hepatitis $\mathrm{C}$ and nonalcoholic fatty liver disease. Arq Gastroenterol. 2015;52:234-8.

3. Rockey DC, Caldwell SH, Goodman ZD, Nelson RC, Smith AD. Liver biopsy. Hepatology. 2009;49:1017-44.
4. Trovato FM, Atzori S, Musumeci G, et al. Liver and spleen transient elastography and Acoustic Radiation Force Impulse Measurements. Performance and comparison of measurements in the same area concurrently assessed for liver fibrosis by biopsy. Adv Med Sci. 2015;60:300-6.

5. Uslu A, Batur A, Biyik M, Acikgozoglu S. Non-Invasive Evaluation of Liver Fibrosis Using Real-Time Elastography and Comparison of Intercostal and Subcostal Approaches. EJGM. 2015;12:109-13

Canakkale Military Hospital Department of Radiology, Canakkale, Turkey; ${ }^{2}$ Van Military Hospital Department of Infectious Diseases, Istanbul, Turkey; ${ }^{3}$ GATA Haydarpasa Training Hospital Department of Radiology, Istanbul, Turkey.

Correspondence: Dr. Coskun Ozturker. Department of Radiology, Canakkale Military Hospital, 17000, Cevatpasa/Canakkale, Turkey. E-mail: drozturker@gmail.com 